\title{
Using Digital Libraries to Engage the Whole Student: Culturally Sustaining Pedagogies, Trauma-Informed Classrooms, and Project-Based Learning
}

\author{
Alejandra Torres
}

\begin{abstract}
Engaging students with an online library does not have to be limited to research purposes only. This essay includes lesson plan ideas that use the Louisiana Digital Library to engage middle and high school students in ways that help amplify their curiosity and explore their identities. To ensure the lesson plans engage the whole student, I ground them in three components (culturally sustaining pedagogies, trauma-informed classrooms, and project-based learning) and seven core values. These lessons could be used alone as writing workshops or can be used to introduce or make connections to other concepts. The activities are adaptable to fit different contexts and could be done in 60 minutes or could be extended or shortened depending how much time you want to give students to share their work with one another.
\end{abstract}

Keywords: Digital library, literacy, culturally sustaining pedagogy, trauma-informed classrooms, project-based learning, lesson plans

Torres, Alejandra. "Using Digital Libraries to Engage the Whole Student: Culturally Sustaining Pedagogies, Trauma-Informed Classrooms, and Project-Based Learning." Special Issue, Journal of Critical Digital Librarianship 1, no. 1 (Fall 2021): 43-55. 


\section{INTRODUCTION}

Engaging middle and high school students with a digital library does not have to be limited to research purposes only. A digital library, such as the Louisiana Digital Library (LDL), can be an avenue for students to amplify their curiosity and explore their own identities. In this essay, I will provide lesson plan structures and ideas that will allow students to creatively engage with the LDL. Based on my background in teaching, I hope to offer a hands-on and practical guide for others involved in both education and digital library practice.

\section{CULTURALLY SUSTAINING PEDAGOGIES, TRAUMA-INFORMED CLASSROOMS, PROJECT-BASED LEARNING}

Before diving into these lesson plans to amplify engagement, I will provide an overview of the framework on which these lesson plans are grounded. These lesson plans are based on a Humanities Amped Seven Core Assets Framework. ${ }^{1}$ Humanities Amped is an educational nonprofit based in Baton Rouge, Louisiana, with the mission to empower public school communities and youth organizations to cultivate healing justice, radical imagination, and beloved community through healing-centered and culturally-sustaining practices. ${ }^{2}$ My experience working with Humanities Amped has shaped my views of pedagogical possibilities, and in this essay I map my experience to the affordances of the LDL to offer a practical guide to engaging the full student through digital library teaching. This framework is a synthesis of three main components: culturally sustaining pedagogies, trauma-informed classrooms, and project-based learning. Culturally sustaining pedagogies are a teaching and learning practice that recognizes that human development and learning cannot be separated from a person's multiple expressions of identity. ${ }^{3}$ For example, a student's race, social class, gender, language, sexual orientation, nationality, religion, ability, and other aspects of their identity cannot be divorced from their learning experiences. Consequently, since identity is tied to learning, culturally sustaining pedagogies allow students to deepen their understanding of their identity and develop a critical consciousness of how the systems around them may affirm or marginalize different parts of their identity.

\footnotetext{
${ }^{1}$ As of October 2021, "Humanities Amped 7 Core Assets Framework: Guiding Questions and Indicators" is available to view here: https://drive.google.com/file/d/1AHkERTgEhkGC6iSfbdCRRGz8nW0fgr4D/view

${ }^{2}$ For more information on these practices visit https://www.humanitiesamped.org/about.html

${ }^{3}$ For more on culturally relevant pedagogy, see: Gloria Ladson-Billings, "Toward a Theory of Culturally Relevant Pedagogy," American Educational Research Journal 32, no. 3 (1995): 465-491, https://doi.org/10.3102/00028312032003465; Gloria Ladson-Billings, "Culturally Relevant Pedagogy 2.0: aka the Remix," Harvard Educational Review 84, no. 1 (Spring 2014): 74-84, https://doi.org/10.17763/haer.84.1.p2ri131485484751; Geneva Gay, "Preparing for Culturally Responsive Teaching," Journal of Teacher Education 53, no. 2 (2002): 106-116, https://doi.org/10.1177/0022487102053002003; and Django Paris, "Culturally Sustaining Pedagogy: A Needed Change in Stance, Terminology, and Practice," Educational Researcher 41, no. 3 (2012): 93-97, https://doi.org/10.3102/0013189X12441244.
} 
The second component of the framework is trauma-informed classroom practices. Not only do students walk into a classroom with complex identities, but they also walk into a classroom having had diverse life experiences, including traumatic experiences. Therefore the framework also draws from the United States Substance Abuse \& Mental Health Service Administration's (SAMHSA) complementary guidance for trauma-informed approaches. ${ }^{4}$ The Humanities Amped Seven Core Asset framework is grounded in the insights of urban educator and youth development specialist Shawn Ginwright. ${ }^{5}$ Ginwright argues that in order to address trauma, educators must help students actively participate with their own healing. As opposed to framing students as passive victims who cannot actively engage in a healing process, Ginwright promotes a framework that allows students to think through the systemic root causes of trauma and engage with ways to transform those systemic injustices in order to advance their healing and the healing needed in their community.

Since both culturally-sustaining and healing-centered approaches require active participation from students, the third component of the framework is project-based learning (PBL). ${ }^{6} \mathrm{PBL}$ is a teaching method in which students learn by actively engaging in real-world and personally meaningful projects. It is through hands-on learning where students can learn more deeply. As opposed to centering learning as something separate from the world around them, project-based learning leans into learning skills through lessons and activities that have real world applications. PBL centers problem posing and solving through a process where students engage in an inquiry process that is authentic and of their own choosing. They are then able to reflect on their learning and produce a public product after cycles of critique and revision.

\section{Seven Core Assets}

Culturally-sustaining, healing-centered, project-based learning are the three umbrellas that the Humanities Amped seven core assets are nested under. The seven core assets are: identity; skill-building; intellect; criticality; safety; trustworthiness \& transparency; peer support; and collaboration, mutuality, empowerment, voice $\&$ choice. Classroom activities are most meaningful when they lead students to develop the seven core values, which I will now outline. The first four assets based on culturally-sustaining pedagogy are: 1) identity, 2) skill-building, 3) intellect, and 4) criticality. In terms of

\footnotetext{
${ }^{4}$ Substance Abuse and Mental Health Services Administration, SAMHSA's Concept of Trauma and Guidance for a Trauma-Informed Approach, HHS Publication No. (SMA) 14-4884, (Rockville: Substance Abuse and Mental Health Services Administration, 2014), https://ncsacw.samhsa.gov/userfiles/files/SAMHSA Trauma.pdf.

${ }^{5}$ Shawn Ginwright, Hope and Healing in Urban Education: How Urban Activists and Teachers are Reclaiming Matters of the Heart (New York: Routledge, 2016); and Shawn Ginwright, "The Future of Healing: Shifting from Trauma Informed Care to Healing Centered Engagement," Medium, May 31, 2018, https://ginwright.medium.com/the-future-of-healing-shifting-from-trauma-informed-care-to-heal ing-centered-engagement-634f557ce69c.

${ }^{6}$ To learn more about project-based learning, see pblworks.org.
} 
identity, research has found that when students see themselves in the curriculum and their multiple identities are affirmed, students have increased opportunities for academic success. ${ }^{7}$ An identity-rich classroom also allows students to think critically about the identities of others and thus increase their empathy and build their social skills. ${ }^{8}$ In addition to social skills, building skills in general is another key asset that is often not fully integrated into a curriculum. For example, writing skills and soft skills (active listening, communication, interpersonal skills, etc.) are often taught in a vacuum separate from the main lesson.

Studies show that employers value soft skills and feel as though schools do not fully teach students these skills. ${ }^{9}$ To increase skill-building, instructors should design lessons that are explicit about the skills that are being cultivated. Authentic skill-building requires students to be able to name the skills they are building, reflect on their growth, as well as assess their peers' growth. Likewise, intellect allows students to grow their ability to critique and revise as students engage in projects that are meaningful because they have real world applications. For example, students may care more about learning about food deserts in their neighborhood and ways to advocate for food security because this is a matter that is important to them. Along that same vein, criticality allows students to think deeply about the roots of systemic injustices. Criticality encourages students to analyze the connections between history, power, and equity in the world around them and think about ways they may be able to advocate for change. ${ }^{10}$

The next four assets are safety; trustworthiness \& transparency; peer support; and collaboration, mutuality, empowerment, voice \& choice. As mentioned above, students step into the classroom with their life experiences and often unprocessed trauma. As studies on trauma demonstrate, students cannot deeply learn when they do not feel safe or included. ${ }^{11}$ Therefore, activities which promote safety, trustworthiness, and transparency allow students to be able to engage more deeply. Similarly, students can offer one another peer support to build mutual care around everyone's well-being. Sharing stories and listening to one another helps students build these relationships and

7 Pedro A. Noguera, "How Racial Identity Affects School Performance," Harvard Education Letter 19, no. 2 (March/April 2003),

https://www.hepg.org/hel-home/issues/19 2/helarticle/how-racial-identity-affects-school-perfor mance 244.

${ }^{8}$ Gholdy Muhammad, Cultivating Genius: An Equity Framework for Culturally and Historically Responsive Literacy (New York: Scholastic Incorporated, 2020).

9 “New Survey: Demand for 'Uniquely Human Skills' Increases Even as Technology and Automation Replace Some Jobs," Cengage Group, January 16, 2019, https://www.cengagegroup.com/news/press-releases/2019/new-survev-demand-for-uniquely-hu man-skills-increases-even-as-technology-and-automation-replace-some-jobs/; "The Future of Jobs and Jobs Training," Pew Research Center, May 3, 2017, https://www.pewresearch.org/internet/2017/05/03/the-future-of-iobs-and-iobs-training/.

${ }^{10}$ For more information on these four specific assets see, Gholdy Muhammad's Cultivating Genius: An Equity Framework for Culturally and Historically Responsive Literacy, noted above.

${ }^{11}$ Ginwright, Hope and Healing in Urban Education. 
in turn a spirit of collaboration and mutuality. As a clustered asset, collaboration, mutuality, empowerment, voice, and choice promotes both student independence and healthy group dynamics which center on consensus-based decision-making.

\section{LITERATURE REVIEW ON DIGITAL LIBRARIES AND CLASSROOM INSTRUCTION}

Educators centering their teaching in these seven assets engage the whole student by promoting approaches that are more interactive and based on the interest of the student. The key then to engaging the whole student with a digital library is to make the engagement apply to what is familiar to the student and what may spark their curiosity. In this engagement process, critical skillbuilding takes place. This framework pairs well with digital libraries.

Several authors in archival studies and related disciplines have pointed out the benefits of using digital libraries as a means to build critical skills. For instance, authors of the whitepaper "Teaching with Digital Primary Sources: Literacies, Finding and Evaluating, Citing, Ethics, and Existing Models" outline how digital primary sources, such as those available through digital libraries, help build information literacy, digital literacy, archival intelligence, primary source literacy, visual literacy, and data information literacy. ${ }^{12}$

In a digital age of social media, students interact constantly with images. Consequently, all of these literacies are critical to build so students can hone their abilities to understand the connections between representations of images, activities, and their social contexts. Teaching analysis of primary document images from a digital library is one way students can practice how to find, access, interpret, and utilize multiple forms of information. ${ }^{13}$ It is also worth pointing out that engaging with digital libraries is not limited to history classes. Students can engage with primary documents and gain skills that transfer to disciplines outside of the humanities.

Educators have noted digital libraries help students practice self-directed reference learning at a pace with which they are comfortable. However, educators' willingness to use digital libraries is connected to their perceived personal competence with using this technology. ${ }^{14}$ In a world still submerged in a pandemic with some schools still using remote or hybrid models, digital libraries can serve as a critical pedagogical resource, especially for students who cannot go in person to physical library archives. For instance, the Louisiana Digital Library (LDL) has assisted with course-specific collections

\footnotetext{
${ }^{12}$ Brianna Gormly et al. "Teaching with Digital Primary Sources: Literacies, Finding and Evaluating, Citing, Ethics, and Existing Models," \#DLFteach, October 7, 2019, https://doi.org/10.21428/65a6243c.6b419f2b.

${ }^{13}$ Peter Carini, "Information Literacy for Archives and Special Collections: Defining Outcomes," Libraries and the Academy 16, no. 1 (January 2016): 197-206, http://doi.org/10.1353/pla.2016.0006.

${ }^{14}$ A. Abrizah and AN Zainab, "Digital Libraries in the Classroom: Secondary School Teachers' Conception," Journal of Librarianship and Information Science 43, no. 4 (2011): 224-36, https://iournals.sagepub.com/doi/abs/10.1177/0961000611418811.
} 
as well as general popular research subjects. ${ }^{15}$ The LDL partners with over 30 cultural heritage institutions to be able to provide more than 236,000 images, 70,000 newspaper pages, 100 oral histories, and 104,000 pages of books and manuscripts. For students in Louisiana, this wide variety of primary resources from their state can help them think critically about their identities since they are able to be engaged with places, foods, settings, etc with which they may already be familiar. Similarly, teachers in other states might consider using a digital library that reflects their own students' environment to increase student interest and peak their curiosity.

\section{USING THE LDL TO ENGAGE WITH THE WHOLE STUDENT}

The three lesson plans included here are highly adaptable and can be used as introductions to larger units. When using primary sources in digital libraries, best practices recommend providing a learning experience that is sequenced and differentiated to optimize achievement for all learners. They additionally recommend giving a simple demonstration and using engaging images that can connect to student lives. ${ }^{16}$ These lesson plans can also be used to build writing skills and connections among students since they will be actively listening to one another. These lessons follow a similar structure. Each includes a pre-write and discussion time so students can activate thinking through their own experiences. In the second part, the instructor models a search and has a preliminary discussion around an artifact such as a song, photograph, recipe or any other stimulating piece. After this modeling and discussion, students then search for their own artifact, do some reflective writing, and share what they have found. The fourth portion involves students writing more extensively, sharing out loud if they want to, and then doing a whole class reflection on the overall activity to assess what they have learned.

For example, the first lesson plan explores recipes in the LDL. Analyzing recipes and then writing their own recipes allows students to think critically about sequencing and writing clear directions within a context such as food that feels like lower stakes. The familiarity of a topic such as food connects to the core asset of safety, trustworthiness, and transparency. It also connects to the core asset of identity as they think about recipes that are familiar to them. This lesson could be used to introduce more unfamiliar concepts such as fractions, measurement conversions, food studies, instructions for coding, or other lessons around sequencing directions. The first part of the lesson includes a pre-writing and discussion. Pre-writing allows students to practice their writing-skills as they ease into the lesson, and classroom discussion promotes the core asset of collaboration, mutuality, empowerment, voice, and choice. At the beginning of

\footnotetext{
${ }^{15}$ Leah Duncan Powell and Sophia Ziegler, "Creating Collaborative Subject Guides for Multi-Institutional Digital Collections: A Case Study from the Louisiana Digital Library," Codex: Journal of the Louisiana Chapter of the ACRL 5, no. 4 (2020): 17-32, http://journal.acrlla.org/index.php/codex/article/view/178.

${ }^{16}$ Eleanor Dickson et al. "Constructing Digital Praxis: Pedagogy for Digital Collections," October 23, 2017, http://doi.org/10.17605/OSF.IO/QGUAW.
} 
the lesson, the instructor asks these questions:

- Do you ever cook?

- Who cooks in your family?

- What is your favorite recipe?

These questions activate student identity as they think about how recipes fit into the context of their own lives. Students can have a moment to write on their own before sharing their responses with one another. In accordance with the core asset of transparency and skill-building, the instructor then shares with the students the skills that this lesson will help them build, and the instructor should provide an overview of the LDL as a digital library. The instructor projects the LDL home page and asks students to pull up the LDL home page as well. The instructor then models for students how to search for a topic in the search bar. Many LDL items that could be used for this lesson can be found in the "Baton Rouge Cookbooks" collection. ${ }^{17}$ Based on items in this collection, the class can discuss the following questions:

- What year is this from?

- What is the title?

- What stands out to you?

These questions help students begin to think about the year and context of the recipe as well as connect with aspects of the artifact that are interesting to them. Following the discussion, students can now search for a recipe in which they are interested. The instructor can then ask students to answer the following questions about their chosen recipe on a handout, digitally, or in whatever mode works for the class. The questions are:

- What is the link?

- What year is this from?

- What is the title?

- What stands out to you?

- Would you be able to find these ingredients at your local store?

These questions engage student criticality as they think about the year and it's context and how some ingredients may change over time while others may never change. After allowing students a few minutes to write about their entry, the instructor can ask two to five students to share their responses. After sharing, the instructor asks students to write a recipe for their favorite food, including ingredients, measurements, and clear instructions. The instructor could also open the recipe to abstract concepts such as the

\footnotetext{
${ }^{17}$ Baton Rouge Cookbooks Collection, East Baton Rouge Parish Library, Louisiana Digital Library,
} https://louisianadigitallibrary.org/islandora/obiect/ebrpl-p16340coll6\%3Acollection. 
recipe for a good friend, the perfect summer day, or the ideal school. Once students have had five to ten minutes to write, students can share their responses. As a closing activity students can write and then share about what they learned about writing instructions, what new thoughts they had, or what they appreciated about the activity.

This share-out allows students to hear from each other and learn more about each other as one form of the core asset of peer support. However, there are some follow up activities or lesson plans which could help extend the core assets of peer support as well as intellectual development and criticality. Follow-ups from this lesson could include students giving feedback on each other's recipes and then posting the recipes online or in a public place that allows students to feel like their work lives outside of their classroom. Students could also make videos of themselves cooking these foods and post them online. Moreover, students could engage in a critical analysis of the recipes found in the LDL and find gaps in representation.

A similarly-structured second lesson plan might be focused around architecture. For this lesson, students will use houses to critically think about writing in detail and describing settings. This lesson could also be used to introduce housing justice, architecture, a historical period, city planning, or any other architectural unit. Once again the pre-writing, discussion, and identity-centered prompt centers the core assets of: identity; skill-building; safety, trustworthiness, and transparency; and collaboration, mutuality, empowerment, voice, and choice. In the pre-writing and discussion, the instructor asks these questions:

- What would your dream house look like?

- How many rooms?

- What special features?

- How does it make you feel?

These questions similarly activate the core assets of identity and voice and choice as students think about what could be possible for them in terms of a dream house. After allowing students a few minutes to write about their entry, the instructor can ask two to five students to share their responses. Once again, the instructor projects the LDL homepage and asks students to navigate to it as well. The instructor models for students how to search for a topic in the search bar. An example of an LDL item that can be used for this lesson is a digital turn-of-the-century photograph of a house held in the Louisiana State Museum LDL collection. ${ }^{18}$ Based on this entry, the class can discuss the following questions:

- What year is this from?

- What is the title?

- What stands out to you?

18 "House," George Francois Mugnier Collection, Louisiana State Museum, Louisiana Digital Library, https://louisianadigitallibrary.org/islandora/object/Ism-gfm\%3A1105. 
These questions engage students' visual literacy and the core asset of criticality as they look at houses from across time. Following the discussion, students can now search for an image of a house of their choosing. The instructor is transparent about the amount of time students have to find their own house. As above, the instructor also asks students to answer the following questions about their chosen house:

- What is the link?

- What year is this from?

- What is the title?

- What stands out to you?

Students once again write about their entry and then have an opportunity to share their responses which incorporates the core assets of peer-support, collaboration, mutuality, empowerment, voice, and choice.

After sharing, the instructor asks students to respond to one of the following two prompts using as many details as possible.

- Prompt one: Write a story about the house from the house's perspective. Who lives there? What do they do? How many rooms? What do the rooms look like?

- Prompt two: Write as if you lived in the house. What does your typical day look like? Who lives with you and what do they do? Do you have pets? What does your room look like? What's your favorite room?

These prompts allow students to build descriptive skills and think about the visual representation of the house they are writing about. Once students have had five to ten minutes to write, students can share their responses. As a closing activity students can share what they learned about writing with details, what new thoughts they had, or what they appreciated about the activity. Other variations could include students drawing their own house.

Ways to expand this lesson around the core assets of criticality and intellectually is for students to consider what the houses in their neighborhoods look like in comparison to other neighborhoods. If there are disparities in the neighborhoods, they could ask themselves what may be the structural and historical context at the root of local housing disparities. In conjunction-to apply more of the research skills they have learned-students could dig into researching the systemic causes in news articles, city documents, and other related documents to create a timeline of the area where they live. They could then post these timelines online or share with local activists in their area.

A final lesson plan suggestion is focused around animal studies. For this lesson, students will critically examine their relationship with animals. This lesson could be used in conjunction with lessons on animal studies, personification, anthropomorphism, 
animal rights, posthumanism, or fables. During the pre-writing and discussion, the instructor asks these questions:

- What is your relationship with animals?

- How do you interact with animals in your life?

- Do you have pets?

- Are you afraid of certain animals?

- Which animals are your favorite?

Once again, the instructor projects the LDL homepage and asks students to pull it up. The instructor models for students how to search for a topic in the search bar. An example of an LDL item that can be used is the photograph titled "Women and their animals." ${ }^{19}$ Based on this entry, the class can discuss the following questions:

- What year is this from?

- What is the title?

- What stands out to you?

- If there are humans in the picture, what appears to be the relationship between the human and the other animals?

- Is this primary document worth preserving? Why or why not?

These questions highlight the core asset of intellectual development through students thinking both about their critical relationship with animals and to start to think critically about what primary documents should be preserved and why. Following the class discussion, students can now search for "animals" in the search bar and find a photo, article, song, or other artifact that appeals to them. The instructor can then ask students to answer the previous questions. After allowing students a few minutes to write about their entry, the instructor can ask a few students to share their responses. The class can go deeper into the dialogue about their entries and make their cases of why the document should be worth preserving. As a closing activity, students can once again reflect on what they learned or what they appreciated about the activity.

A way to further expand on this lesson to highlight intellectual development and criticality is for students to look more critically at the digital library as a whole and the types of primary documents that may be missing from the archive. Similar to the other lessons, the core asset of peer support could be amplified through giving constructive feedback to drafts of the work before publishing online. This lesson could also serve as an avenue for local animal shelters to come talk about volunteer opportunities so that there is a tangible connection to their outside community.

\footnotetext{
19 "Women and their animals," Early Images of Latin America Collection, Tulane University Digital Library, Louisiana Digital Library, https://louisianadigitallibrarv.org/islandora/obiect/tulane-p16313coll16\%3A3347.
} 


\section{CONCLUSION}

Not all schools have access to the internet, reliable internet connections, or equipment that allows them to have access to digital libraries. However, for those schools that do, these three lesson plans follow the framework of engaging student identity, intellect, and criticality as they think their way through the lesson. They also build skills through detailed writing and learning to navigate search tools on a digital library. As opposed to a formal assessment, the reflection at the end organically allows students to identify for themselves what they learned or appreciated. In terms of healing-centered learning, these activities also allow students to build trust with one another as they listen to each other's favorite recipes or dream houses.

Learning more about each other helps students build relationships and witness each other's humanity. They also have a sense of empowerment and choice as they are the ones who get to choose which primary document to write about. When instructors promote these seven assets, then student engagement increases. A lesson plan can be more effective and humanized when students find it meaningful. Moreover, using digital libraries in schools highlights the importance of inclusive and ethical representation in digital libraries as a whole. All students should be able to see parts of themselves in the archive as they build their skills to critically examine and advocate for equitable representation. 


\section{BIBLIOGRAPHY}

Abrizah, A., and AN Zainab. "Digital Libraries in the Classroom: Secondary School Teachers' Conception." Journal of Librarianship and Information Science 43, no. 4 (2011): 224-36. https://journals.sagepub.com/doi/abs/10.1177/0961000611418811.

Carini, Peter. "Information Literacy for Archives and Special Collections: Defining Outcomes." Libraries and the Academy 16, no. 1 (January 2016): 197-206. http://doi.org/10.1353/pla.2016.0006.

Dickson, Eleanor, Kate Dohe, Lisa Janicke Hinchliffe, Elizabeth Joan Kelly, Chelcie Juliet Rowell, and Angie White. "Constructing Digital Praxis: Pedagogy for Digital Collections." October 23, 2017. http://doi.org/10.17605/OSF.IO/QGUAW.

Gay, Geneva. "Preparing for Culturally Responsive Teaching." Journal of Teacher Education 53, no. 2 (2002): 106-116. https://doi.org/10.1177/0022487102053002003.

Ginwright, Shawn. Hope and Healing in Urban Education: How Urban Activists and Teachers are Reclaiming Matters of the Heart. New York: Routledge, 2016.

Ginwright, Shawn. "The Future of Healing: Shifting from Trauma Informed Care to Healing Centered Engagement." Medium, May 31, 2018.

https://ginwright.medium.com/the-future-of-healing-shifting-from-trauma-infor med-care-to-healing-centered-engagement-634f557ce69c.

Gormly, Brianna, Maura Seale, Hannah Alpert-Abrams, Andi Gustavson, Angie Kemp, Thea Lindquist, and Alexis Logsdon. "Teaching with Digital Primary Sources: Literacies, Finding and Evaluating, Citing, Ethics, and Existing Models." \#DLFteach, October 7, 2019. https://doi.org/10.21428/65a6243c.6b419f2b.

Ladson-Billings, Gloria. "Culturally Relevant Pedagogy 2.0: aka the Remix." Harvard Educational Review 84, no. 1 (Spring 2014): 74-84. https://doi.org/10.17763/haer.84.1.p2ri131485484751.

Ladson-Billings, Gloria. "Toward a Theory of Culturally Relevant Pedagogy." American Educational Research Journal 32, no. 3 (1995): 465-491. https://doi.org/10.3102/00028312032003465.

Louisiana Digital Library, https://louisianadigitallibrary.org.

Muhammad, Gholdy. Cultivating Genius: An Equity Framework for Culturally and Historically Responsive Literacy. New York: Scholastic Incorporated, 2020. 
“New Survey: Demand for 'Uniquely Human Skills' Increases Even as Technology and Automation Replace Some Jobs." Cengage Group. January 16, 2019. https://www.cengagegroup.com/news/press-releases/2019/new-survey-deman d-for-uniquely-human-skills-increases-even-as-technology-and-automation-repla ce-some-jobs/.

Noguera, Pedro A. "How Racial Identity Affects School Performance." Harvard Education Letter 19, no. 2 (March/April 2003).

https://www.hepg.org/hel-home/issues/19 2/helarticle/how-racial-identity-affe cts-school-performance 244.

Paris, Django. "Culturally Sustaining Pedagogy: A Needed Change in Stance, Terminology, and Practice." Educational Researcher 41, no. 3 (2012): 93-97. https://doi.org/10.3102/0013189X12441244.

Powell, Leah Duncan and Sophia Ziegler. "Creating Collaborative Subject Guides for Multi-Institutional Digital Collections: A Case Study from the Louisiana Digital Library." Codex: Journal of the Louisiana Chapter of the ACRL 5, no. 4 (2020): 17-32. http://journal.acrlla.org/index.php/codex/article/view/178.

Substance Abuse and Mental Health Services Administration. SAMHSA's Concept of Trauma and Guidance for a Trauma-Informed Approach. HHS Publication No. (SMA) 14-4884. Rockville: Substance Abuse and Mental Health Services Administration, 2014. https://ncsacw.samhsa.gov/userfiles/files/SAMHSA Trauma.pdf.

"The Future of Jobs and Jobs Training." Pew Research Center. May 3, 2017. https://www.pewresearch.org/internet/2017/05/03/the-future-of-jobs-and-jobs -training/. 